Int. J. Electrochem. Sci., 15 (2020) 8375 - 8385

International Journal of

ELECTROCHEMICAL

SCIENCE

WWW.electrochemsci.org

\title{
Electrochemical Study of Carbon Steel and 304 Stainless Steel Erosion Behavior in Sand-Containing Water
}

\author{
Teng Wu ${ }^{1, *}$, Yixuan Liu $^{1}$, Jie Qin ${ }^{1}$, Yan Wang ${ }^{2}$, Shengnan Ye, Xinguo Feng ${ }^{1}$, Shengli Chen ${ }^{3}$ \\ ${ }^{1}$ Jiangsu Key Laboratory of Coast Ocean Resources Development and Environment Security, Hohai \\ University, Nanjing 210098, Jiangsu, China \\ ${ }^{2}$ Hangzhou Jinghang Canal Second Channel Construction Investment Co., Ltd. Hangzhou 310000, \\ Jiangsu, China \\ ${ }^{3}$ CNOOC information technology Co., Ltd. Oceanographic information Center, Beijing 100013, China \\ *E-mail: wuteng@hhu.edu.cn
}

doi: $10.20964 / 2020.09 .78$

Received: 2 May 2020 / Accepted: 15 July 2020 / Published: 10 August 2020

\begin{abstract}
The effects of rotational speed and sand concentrations on the wear behavior on carbon steel and stainless steel were investigated by open-circuit potential, polarization curves, electrochemical impedance spectroscopy and scanning electron microscopy. The mass loss rates of samples under each condition were determined. The erosion rates of both steels increased with the rotational speed and sand concentration, and the erosion rates of the 304 stainless steel were approximately one-tenth of the carbon steel for the same conditions in the sand-containing water. The erosion rate that was calculated from the polarization curve method was similar to the tested mass loss results, and can be used to determine the erosion rate in flowing sand-containing water.
\end{abstract}

Keywords: Erosion, stainless steel, carbon steel, electrochemical test

\section{$\underline{\text { FULL TEXT }}$}

(C) 2020 The Authors. Published by ESG (www.electrochemsci.org). This article is an open access article distributed under the terms and conditions of the Creative Commons Attribution license (http://creativecommons.org/licenses/by/4.0/). 